\title{
PRECEDENTE ADMINISTRATIVO OU JURISPRUDÊNCIA ADMINISTRATIVA: A FORÇA NORMATIVA DO ART. 30 DA LEI DE INTRODUÇÃO ÀS NORMAS DO DIREITO BRASILEIRO
}

\section{ADMINISTRATIVE PRECEDENT OR ADMINISTRATIVE JURISPRUDENCE: THE NORMATIVE ENFORCEMENT OF ART. 30 OF THE LAW OF INTRODUCTION TO THE RULES OF THE BRAZILIAN LAW}

Recebimento: 20 maio 2020

Aceitação: 3 set. 2020

\begin{abstract}
Juliano Heinen
Doutor em Direito

Afiliação institucional: Procuradoria-Geral do Estado do Rio Grande do Sul (Porto Alegre, RS, Brasil)

Lattes iD: http://lattes.cnpq.br/7687802519468461

Email: julianoheinen@hotmail.com
\end{abstract}

Como citar este artigo / How to cite this article (informe a data atual de acesso / inform the current date of access):

HEINEN, Juliano. Precedente administrativo ou jurisprudência administrativa: a força normativa do art. 30 da Lei de Introdução às normas do Direito Brasileiro. Revista da Faculdade de Direito UFPR, Curitiba, v. 66, n. 1, p. 149-167, jan./abr. 2021. ISSN 2236-7284. Disponível em: https://revistas.ufpr.br/direito/article/view/73900. Acesso em: 30 abr. 2021. DOI: http://dx.doi.org/10.5380/rfdufpr.v66i1.73900.

\section{RESUMO}

O presente trabalho pretende analisar a aplicação jurídica e os efeitos gerados com a vigência do artigo 30 da Lei de Introdução às normas do Direito Brasileiro, percebendo o que é alterado no contexto jurídico nacional. Primeiro, diferencia-se jurisprudência de precedente. Por conseguinte, esses conceitos são transportados ao contexto do processo administrativo. Com base nessas premissas teórico-dogmáticas, analisam-se os efeitos do referido dispositivo legal. Ao final será apresentada sua utilidade e suas possibilidades de aplicação pelos juristas. Para dar um caráter pragmático, entregase, derradeiramente, uma metodologia de como aplicar objetivamente o dispositivo legal analisado. Assim, a presente pesquisa contém uma lista de limites e possibilidades para a aplicação teóricopragmática do instituto, a partir da revisão bibliográfica proposta. Optou-se por estruturar a pesquisa por meio do método de abordagem dedutivo e exploratório, conformando o detalhamento do tema a partir de precisões dogmáticas, para se conseguir alcançar as conclusões, respondendo quais são os limites e possibilidade de aplicação do mencionado artigo 30 da referida legislação.

\section{PALAVRAS-CHAVE}

Precedente administrativo. Jurisprudência administrativa. Vinculatividade.

\section{ABSTRACT}

The present work intends to analyze the legal application and the effects generated with the enactment of article 30 of the Law of Introduction to the rules of the Brazilian Law, realizing what is changed in the national legal context. First, precedent is differentiated from jurisprudence. Consequently, these concepts are carried over to the context of the administrative process. Based on these theoretical- 
dogmatic premises, the effects of this legal provision are analyzed. At the end, its utility and its possibilities of application by lawyers will be presented. To give it a pragmatic character, a methodology of how to objectively apply the analyzed legal device is also presented. Thus, the present research contains a list of limits and possibilities for the theoretical-pragmatic application of the institute, based on the proposed bibliographic review. It was decided to structure the research using the deductive and exploratory approach method, conforming the detail of the theme based on dogmatic precision, in order to reach the conclusions, answering what are the limits and the possibility of applying the mentioned article 30 of the referred legislation.

\section{KEYWORDS}

Administrative precedent. Administrative jurisprudence. Binding effects.

\section{INTRODUÇÃO}

As decisões proferidas na esfera administrativa, oriundas da atividade consultiva, ganham eficácia jurídica vinculante com a vigência do art. 30 do Decreto-Lei $n^{\circ} 4.657$, de 4 de setembro de 1942 (Lei de Introdução às normas do Direito Brasileiro), inserido pela Lei $n^{0}$ 13.655/2018. Não podem mais ser categorizadas como mera opinião jurídica, mas sim, como fontes do direito. Logo, é original explorar como esse dispositivo pode ser aplicado e quais as possibilidades jurídicas. Nesse contexto, facilita a análise crítica do tema, pelo método exploratório, a aplicação do instituto da autolimitação administrativa, também aqui detalhado.

Se isso é verdadeiro, o que muda no contexto jurídico brasileiro? Qual seria a utilidade e suas possibilidades de aplicação pelos juristas? Quais os ganhos sociais? Essas são perguntasproblema a serem respondidas dedutivamente neste trabalho, que pretende ofertar uma lista de limites e possibilidades para a aplicação teórico-pragmática do instituto, a partir da revisão bibliográfica proposta.

Tal análise se mostra relevante, na medida em que investiga as potencialidades de aplicação da jurisprudência e dos precedentes administrativos de modo vinculante. A rigor, tal regra jurídica transforma uma compreensão teórico-dogmática em norma (padrão deontológico), o que torna significativa uma compreensão científica do instituto.

Como resultado, será importante e útil entregar ao leitor uma metodologia de como o instituto pode ser aplicado, seus efeitos jurídicos e seus limites. Essa entrega visa a facilitar e a construir um cenário teórico-dogmático sobre o tema. São itens que devem ser implementados para cada manifestação da autolimitação poder vir a incidir. Significa dizer que o leitor, caso concorde com o entendimento acerca do tema, contará com uma radiografia exata e operacional para o uso de cada um dos institutos analisados. Como se, para aplicá-los, devesse “completar” verdadeiro checklist. 


\section{A LÓGICA DO PRECEDENTE E DA JURISPRUDÊNCIA}

A Lei de Introdução às normas do Direito Brasileiro (LINDB), especialmente nos artigos 22 a 30, que é o tema que aqui interessa, não tem o condão de tutelar direitos subjetivos, mas o próprio Direito Público, por meio de condicionantes de validade das decisões. Elege uma série de parâmetros em temas variados, a fim de auxiliar o intérprete na aplicação do referido direito. O artigo 30, aqui comentado, tem por objeto qualificar e aperfeiçoar o desenho institucional da ordem normativa quanto ao tema da segurança jurídica. E se isso foi necessário, é porque o direito brasileiro convive com a indeterminação e a contingência.

E não é só. Tal dispositivo realça a figura do "precedente" ou da "jurisprudência administrativa”, os quais podem ser uma fonte ou materializar a autolimitação administrativa termos estes que podem ter como sinônimo a “autocontenção do Poder Público”, seja ela voluntária ou involuntária (HEINEN, 2018; OTERO, 2003; SADDY, 2013). Em outros termos, esse instituto, seja o nome que se tenha ofertado, é uma clara manifestação instrumental da segurança jurídica, porque permite que a Administração Pública estabeleça padrões decisórios, ou proíbe que essa mesma administração atue, sem critério, contra esse padrão, quando ela mesma gerou essa situação jurídica específica. E tem íntima ligação com o mencionado dispositivo da LINDB. Aqui, ocupar-seá, em um primeiro momento, com a explicação do “sistema de precedentes”, para então tratar da autolimitação administrativa.

Antes de tudo, deve-se ter em mente que “precedente” e "jurisprudência” não se confundem¹. Essas categorias, tão presentes no âmbito do processo civil, podem ser transportadas, guardadas as devidas peculiaridades, ao processo administrativo, desde que se façam algumas adaptações conceituais (v.g. é claro que uma decisão administrativa poderá ser sindicada pelo Poder Judiciário).

A jurisprudência consiste na repetição de julgamentos que levam em conta o dispositivo fixado em casos semelhantes. Então, pode-se dizer que a jurisprudência não surge diante de casos isolados. Ela bem pode se tornar dominante em uma corte, sendo ela prevalente em relação às demais (MARINONI, 2010, passim; MITIDIERO, 2017, p. 70-71).

Já a súmula deriva da jurisprudência. Nada mais é do que o enunciado que resume o entendimento jurisprudencial reiterado - prevalente. Consistiria no texto da ratio decidendi reiterada. A súmula não se confunde com o texto da lei, porque ele vai além, repetindo o texto da

1 As acepções do termo “precedente administrativo” ou “jurisprudência administrativa” foram empregadas de variados modos (conforme apresentação feita em LUVIZOTTO, 2017, p. 109). 
ratio. E, por isso, não se podem interpretar as súmulas como se fossem texto de lei, porque as primeiras derivam de casos concretos: “O reconhecimento de que a súmula vinculante é fonte formal de Direito não significa, em absoluto, equipará-la à norma emitida pelo Poder Legislativo. Não mesmo. A lei e a jurisprudência são fontes do direito, mas fontes distintas, com metódica diversa para a solução das controvérsias jurídicas” (CADORE, 2007, p. 108).

Já os precedentes procuram ofertar diretivas valorativas, ou seja, determinadas por uma escolha ${ }^{2}$. Portanto, o Poder Judiciário, especialmente nas cortes de vértice, passa a deter duas funções importantíssimas ${ }^{3}$ :

(a) colabora e muito para a formação e para a evolução do direito, ou seja, para que o sistema jurídico possa se adequar às necessidades sociais. Enfim, passa a deter o papel de atribuição de sentido à lei, como tarefa genuinamente criativa;

(b) ao mesmo tempo, consegue consagrar-se como guardião da manutenção do sistema jurídico, fornecendo, pela via dos precedentes, a pretendida segurança jurídica - o que é reforçado, claro, pela permanência dos sentidos já ofertados e pela vinculatividade dos próprios precedentes.

Além disso, deve ser lembrado, por oportuno, que o civil law criou as cortes de cassação justamente para se “dar exato sentido à lei”, ou seja, estavam baseadas no formalismo interpretativo. Sendo assim, as cortes superiores eram vistas como tribunais de correção e de revisão. Essas funções não estão presentes nas cortes do common law, que se baseiam no sistema de precedentes. E essa premissa, então, deverá ser inserida no contexto do processo civil contemporâneo.

No Brasil, hoje, pratica-se o direito a partir de instituições moldadas a partir do século XIX, ou seja, um direito dito "pré-kelseniano”. A mudança ocorrida no século XX, a partir do esquema conceitual derivado da Teoria Pura do Direito (de 1934), parece que nem sequer foi totalmente incorporada nesse País (KELSEN, 1995). No último capítulo da obra, Kelsen diz que, ao contrário do que se supunha no século XIX, a interpretação não pode, jamais, levar a uma reposta unívoca e correta.

O máximo que a norma oferece é uma “moldura”. E, dentro dela, várias são as aplicações possíveis da própria norma, todas elas legítimas. Essa premissa revoluciona o entendimento até então vigente, advindo dos preceitos teóricos do século que havia sido deixado para trás. Contudo, os

2 Há, nesse aspecto, um impacto significativo do constitucionalismo.

3 Ao que parece, a figura do precedente vem a ser disciplinada nos arts. 926 e 927 do Código de Processo Civil (CPC), apesar de ali estarem contidas as expressões “jurisprudência”, “súmula” e "precedente” de maneira equivocada, tendo em vista que se misturaram os institutos, porque, como dito, a regra fez uma ressignificação dos signos de modo errôneo. 
tribunais nacionais comportam-se como se estivessem diante de uma “solução única”, ou seja, ante uma única aplicação correta. Contudo, até mesmo Kelsen rompeu com esse paradigma.

Em 1961, Herbert Hart lança uma obra bastante importante para a compreensão desse sistema, denominada de “O conceito de direito”. No capítulo sete, o autor dedica-se a tratar exclusivamente da interpretação, que denomina de “ceticismo sobre as regras”4. Diz ele que existem situações em que o direito não provê o julgador com termos precisos, seja por meio de precedentes ou da própria lei. Então, segundo conta, existem grandes grupos de casos em que o precedente se apresenta de maneira clara, unívoca, e, então, o julgador já tem a resposta pronta, dada pelo precedente ou pela lei. Trata-se, aqui, de um caso fácil, cuja solução é dada antes da interpretação (HART, 2005). Essa obra de Hart traz à tona uma crítica bastante qualificada do common law. Por fim, não menos importante no tema, são as coletâneas publicadas por MacCormick e Summers, em 1991 e 1997, as quais trazem um novo caldo de cultura à interpretação das leis e dos precedentes (MACCORMICK; SUMMERS, 1997). São obras importantíssimas na construção do sistema jurídico como um todo e no entendimento das fontes do direito.

Portanto, interpretar não é dar um sentido prévio dado pelo legislador ao texto. Interpretar é reconhecer sentidos mínimos dados pelas palavras, valorar esses significados e decidir por um desses significados. Sendo assim, não se valora um texto, apenas. A atividade de decisão, enfim, resume-se a perfazer uma escolha, ou seja, é preciso decidir o significado do direito.

Em 1980, já no primeiro capítulo de L’interpretazione della legge, Giovanni Tarello trata da interpretação, ocupando, pois, um lugar de destaque na obra. Defende ele que, antes da interpretação, está-se diante de textos. Aliás, estar-se-ia ante, no máximo, “elementos extratextuais”, como o costume. Assim, a norma é resultado da interpretação, e não o objeto dela; enfim, a interpretação originaria um produto denominado de “norma”. É por isso que texto não se confunde com norma, são institutos diversos. Aqui, não se declara a norma, mas se constitui um sentido, ou seja, acresce-se ao direito. Em outras palavras, segundo Tarello (1980), textos são equívocos e normas são vagas, por várias razões: a redação pode ser ambígua, complexa, abstrata, o que faz com que a decisão possa dizer muitas coisas. Além disso, podem deter alto grau de abarcabilidade, fazendo com que muitas coisas possam se encontrar dentro do âmbito de proteção da norma. Então, de um texto podem advir várias normas - admitindo-se, aqui nessa nota, o sentido interpretativo ao signo "norma”.

E, segundo a constituição federal vigente no Brasil, é o Supremo Tribunal Federal (STF) quem dá a última palavra sobre o significado dessa carta de direitos, assim como o Superior Tribunal

4 Em inglês, “rule cepticism”. Cf. HART, 2005, p. 149. 
de Justiça (STJ) o faz em relação ao direito infraconstitucional. Logo, essas instituições atuam como “guias do direito", e por isso não podem ser um reduto que perfaz a tutela do legislador contra o arbítrio dos juízes. Tais órgãos jurisdicionais não apenas controlam a aplicação da lei, mas igualmente, devem fornecer sentidos ao sistema jurídico e fomentar a coerência. Não tem mais sentido essas cortes apenas perfazerem um controle, ou seja, julgar o caso. Especialmente a partir da matriz normativa instituída pelo Código de Processo Civil de 2015.

Assim, a eficácia das decisões da corte deixa de ser de mera jurisprudência. Quiçá será passível de súmula ${ }^{5}$. Veja-se que o sistema que é lastreado na jurisprudência (e não no precedente) adota um critério meramente quantitativo, e não qualitativo. Ao que indica, esse sistema pretende, então, que a jurisprudência reflita o sentido unívoco da norma.

Mas, mesmo assim, o problema da aleatoriedade das decisões não foi solucionado. É por isso que o CPC de 2015 ressignificou os conceitos de "jurisprudência”, "corte suprema” $e$ “precedentes" - ao menos de modo jurídico-positivo. Essa é a tentativa de dar um significado às cortes e, claro, uma função diversa daquelas até então experimentadas. Afinal, não tem mais sentido ver as cortes como entes de tutela da lei contra o juiz. Essa relação de oposição deixa de existir, para dar lugar a uma colaboração entre ambos. E, por isso, o exame casuístico deixa de ser a vedete desses órgãos jurisdicionais, porque não precisam mais examinar inúmeros recursos para formatar um sentido único. Veja-se que um único julgado pode dizer isso e, a partir daí, o sistema jurídico deve se conformar.

Não tem mais sentido, então, fazer com que a corte examine todos os recursos a ela dirigidos. Ela examinará somente aqueles casos relevantes a dar unidade ao sistema jurídico. Ela deve decidir aquilo que irá decidir. E isso não será rediscutido tão cedo.

Veja-se que o precedente não é uma questão de processo, mas de direito, justamente pelo fato de pretender ofertar confiança no/ao direito. Sem segurança jurídica, não há igualdade, porque não se pode ser igual, quando não há como se aplicar de maneira uniforme o direito do qual não se conhece. Afinal, intenta-se que os sujeitos sejam tratados como pessoas pelas quais o direito se compromete.

No âmbito do sistema de precedentes, o julgamento não confere relevância ao caso, ou seja, às pessoas em litígio. O que importa, aqui, são as razões pelas quais se chega a uma ou outra solução.

\footnotetext{
5 Em 1960, o ministro do STF Victor Nunes Leal criou o sistema de súmulas para enfrentar o volume de processos encaminhados àquela corte. Dessa forma, os verbetes, na origem, eram apenas um método de trabalho e, portanto, não poderiam ser vinculantes, porque apenas lembravam como o tribunal deveria julgar. Cf. ALMEIDA, 2006.
} 
E é ainda mais conveniente que fique destacado que, dentro das razões, importam ao precedente somente aquelas que são determinantes à sua formação.

Portanto, será natural o processamento de uma mudança de postura nos julgamentos das cortes superiores e suprema: o voto do relator não deve convidar à adesão, mas sim, ao julgamento. Logo, não se concebe que ele detenha, em seu corpo, itens de definitividade, mas sim, de reflexão ${ }^{6}$. O relator do caso deve ofertar à corte um projeto de discussão que estimule o debate. E, de outro lado, a soma de votos não se mostrará racional para se gerar um precedente, como uma fonte também do direito administrativo. Para se ter uma ideia, o código aprovado em 2015 insere no sistema jurídico nacional os conceitos de distinção ${ }^{7}$ e de superação ${ }^{8}$, típicos do sistema do stare decisis.

A título conclusivo deste tópico, cabe uma palavra final sobre a Teoria do "stare decisis". Ela permite a vinculatividade dos precedentes, a qual foi estabelecida no caso London Street Tramways Company v.s. London County Council, em 18989. Nessa oportunidade, a Câmara dos Lordes inglesa definiu a eficácia vertical dos precedentes, ou seja, sua vinculatividade para com os demais magistrados. De outro lado, apenas no ano de 1966 a mencionada corte explicitou que ela pode superar esse precedente por meio do que denominou de "boas razões", sempre protegendo a confiança legítima das pessoas que praticaram condutas com base no pretendente. Assim, a segurança acaba por ser mantida, bem como a superação não é possível em qualquer hipótese.

\section{PRECEDENTE E JURISPRUDÊNCIA ADMINISTRATIVA}

Transportando essa perspectiva jurisdicional ao âmbito administrativo, a eficácia das decisões promovida nesse campo deixa de ser de mera jurisprudência ${ }^{10}$ (quiçá será passível de súmula), porque o sistema de decisões passa a ser vinculativo, conforme previsão expressa do art. 30, caput e parágrafo único, da LINDB - com redação dada pela Lei n ${ }^{\circ}$ 13.655/2018 ${ }^{11}$. E esses parâmetros

6 CPC, art. 489, § $1^{\text {o: }: ~ N a ̃ o ~ s e ~ c o n s i d e r a ~ f u n d a m e n t a d a ~ q u a l q u e r ~ d e c i s a ̃ o ~ j u d i c i a l, ~ s e j a ~ e l a ~ i n t e r l o c u t o ́ r i a, ~ s e n t e n c ̧ a ~ o u ~}$ acórdão, que: [...] V - se limitar a invocar precedente ou enunciado de súmula, sem identificar seus fundamentos determinantes nem demonstrar que o caso sob julgamento se ajusta àqueles fundamentos”.

7 CPC, art. 489, § $1^{\circ}$, inciso VI; art. 927, § $1^{\circ}$; art. 1.029, § $2^{\circ}$; art. 1.037, §§ $9^{\circ}$ e 12; art. 1.032; art. 1042, § $1^{\circ}$, inciso II; e art. $1043, \S 5^{\circ}$.

8 CPC, art. $927, \S \S 2^{\circ}$ a $4^{\circ}$.

9 Cf., sobre o caso, LAWTEACHER, 2013.

10 Para os limites teóricos deste trabalho, considera-se “jurisprudência” um conjunto de decisões reiteradas de um certo tribunal (MAXIMILIANO, 2011, p. 146), mas que releva o dispositivo dessas decisões.

11 A Lei $n^{\circ}$ 13.655/2018 inseriu o art. 30 no Decreto-Lei no 4.657/1942: “As autoridades públicas devem atuar para aumentar a segurança jurídica na aplicação das normas, inclusive por meio de regulamentos, súmulas administrativas e respostas a consultas. Parágrafo único. Os instrumentos previstos no caput deste artigo terão caráter vinculante em relação ao órgão ou entidade a que se destinam, até ulterior revisão”. 
de autolimitação deverão operar por meio de mecanismos públicos que divulguem as decisões e autovinculem as autoridades que as proferiram (MOREIRA; PEREIRA, 2018, p. 246).

Logo, a decisão passa a deter não mais um critério meramente quantitativo, mas muito mais qualitativo. Ao que indica, esse sistema pretende, então, que a "jurisprudência administrativa” (que se deve denominar, ao menos aqui, de "precedente administrativo”) reflita o sentido unívoco da norma. Sendo assim, por ser apenas uma declaração da norma, não é fonte do direito, como se a interpretação não implicasse decisão de significado.

Ademais, o art. 30 da LINDB, citado logo antes, institucionaliza legalmente a necessidade de respeitar os precedentes administrativos, seja no plano horizontal (relativo ao próprio órgão ou entidade), seja no plano vertical (relativo a todos os agentes subordinados ao órgão que prolatou o precedente). Ademais, tal dispositivo estabelece uma estabilização das decisões que enaltece $e$ qualifica a segurança jurídica, na medida em que os limites acerca da atuação administrativa passam a ser percebidos a partir de parâmetros objetivos - o que pode ser conseguido com a edição de súmulas, regulamentos, respostas às consultas, etc. (MOREIRA; PEREIRA, 2018, p. 247-248).

O sistema de precedentes administrativos acaba por gerar uma norma geral a partir de um caso concreto. Ela estabelece uma prescritividade, fundamentando o caso concreto e aqueles semelhantes que venham a ser então decididos. Para isso, há a necessidade de identidade de argumentos jurídicos, ou seja, de sua reiteração (SASTRE, 2008, p. 239). Assim, tal norma terá como elementos o caso concreto, a argumentação jurídica utilizada e a norma jurídica geral construída para resolver o caso. E, então, constitui-se o precedente administrativo, conforme a disciplina jurídica nacional incidente à espécie. Deve-se lembrar a advertência feita há muito tempo por Themístocles Brandão Cavalcanti, quando o autor discorria sobre a “coisa julgada administrativa”. Declara ele que sua eficácia vai depender de como o regime jurídico assim dispuser: "Há de se considerar, portanto, em primeiro lugar, o mecanismo do regime, a função dos órgãos de jurisdição administrativa ou comum, para apreciar se o prestígio e a força dos atos e decisões administrativas em face dos órgãos de revisão, órgãos jurisdicionais...” (CAVALCANTI, 1956, p. 553) ${ }^{12}$. Lembrando que o dispositivo da decisão se apresenta à solução do caso, e é na fundamentação que se percebe o precedente. De modo que a decisão administrativa que se presta a autolimitar a discricionariedade terá essa dupla perspectiva, com fundamento na segurança jurídica (MOREIRA; GOMES, 2018, p. 255).

\footnotetext{
12 Sobre a vinculatividade da "coisa julgada administrativa”, deve ser mencionado leading case da Suprema Corte brasileira: STF, AR nº 950, Rel. Min. Rafael Mayer, Pleno, j. 26/03/1980. E antes disso: STF, RE nº 31.233, Rel. Min. Antônio Martins Vilas Boas, Pleno, j. 08/08/1958.
} 
Então, pode-se dizer que o precedente administrativo é uma razão universalizável, necessária e suficiente, para a solução de uma questão que não importa só ao presente, mas, principalmente, ao futuro e a todo o País. Ele possui um núcleo, que nada mais é do que a norma jurídica geral que é construída (ratio decidendi). Sendo ela que constitui o caráter prescritivo do precedente, espelha o fundamento normativo da decisão. Como consequência (e após a sua constituição), o sujeito deve compreender como aplicar o precedente $e^{13}$.

Não se tem dúvida de que o precedente e a jurisprudência exercem um papel importante tanto no processo jurisdicional, como no processo administrativo. E essa explicação pode ser justificada, já que tanto o Poder Judiciário, como a Administração Pública dão cabo de aplicar o direito. Afinal, no que diz respeito a essas categorias jurídicas, percebe-se que ambas visam a consolidar as construções jurídicas firmadas, seja a partir da ratio decidendi, seja a partir do dispositivo (GAMBOA, 2010, p. 65).

É importante notar que a doutrina de direito processual (especialmente ligada ao processo civil) possui muita clareza em diferenciar jurisprudência de precedente. Em direito administrativo (ainda que se esteja a falar em processo nessa seara), a diferenciação desses dois institutos não só é obtusa, como, muitas vezes, ambos são tratados como se sinônimos fossem ${ }^{14}$. De qualquer sorte, tanto o precedente administrativo, quanto a jurisprudência administrativa podem constituir exemplo de autovinculação.

Por isso, deixou-se bastante evidente que, especialmente no âmbito do processo civil, há diferença entre jurisprudência e precedente. E se viu, também, que, no âmbito do direito administrativo, "precedente” está a significar uma decisão administrativa vinculativa de condutas futuras - independentemente do conteúdo da vinculação (v.g. se ligada à ratio decidendi ou ao dispositivo). Para os limites teóricos desta obra, será empregada essa última noção, porque aqui basta saber que se trata de uma decisão administrativa autovinculante.

Assim, o “sistema de decisões administrativas” pode vincular, inexoravelmente, casos reiterados e análogos. Quando decididos ou praticados ao longo do tempo, reiteradamente e em um

13 Perceba-se, assim, que se está importando a metodologia de interpretação do precedente, o que gera clara interpenetração do common law no civil law.

14 Por todos: "Precedente administrativo é a atividade interna da Administração Pública, reiterada e uniforme, formando a jurisprudência administrativa, o decidir casos individuais, ao aplicar regras normativas e ao executar outros atos jurídico-administrativos” (MELLO, 2010, p. 393). Em sentido oposto: “[...] precedente administrativo é a norma jurídica extraída de um ato administrativo individual e concreto, do tipo decisório, ampliativo ou restritivo da esfera jurídica dos administrados, e que vincula o comportamento da Administração Pública para todos os casos posteriores e substancialmente similares. Em outras palavras: casos substancialmente similares deverão ter a mesma solução jurídica por parte da Administração Pública” (CARVALHO, 2015, p. 123). Muito embora o autor não explore maiores elementos que diferenciam o precedente e a jurisprudência, como fazem, por exemplo, os doutrinadores do processo civil - pode-se citar: MITIDIERO, 2017, p. 55. 
mesmo sentido, forma-se um padrão. De modo que a Administração Pública, ao agir repetidamente de determinada forma, ou ao decidir por várias vezes de determinada maneira, cria um standard, o qual gera uma expectativa ao administrado. A mudança de critério é possível, desde que desempenhada diante de alguns requisitos.

\section{EFEITOS PRAGMÁTICOS DO ART. 30 DA LINDB}

Por essa perspectiva, a “jurisprudência administrativa” ou o "sistema de precedentes administrativos” é, sem dúvida, uma manifestação da autolimitação administrativa (LUENGO, 2002, p. 227) ${ }^{15}$. O instituto surge na Alemanha, ainda no século XIX, inicialmente atrelado ao direito de igualdade. Tinha por finalidade conferir uma fundamentação à proteção do cidadão ante a aplicação desigual da lei, atuando no combate a arbitrariedades ${ }^{16}$. Tempos depois é que a proteção da confiança foi inserida como fundamento ao instituto (OLIVEIRA, 2018, p. 104).

Aliás, toda vez que uma norma administrativa que confira um determinado espaço de liberdade for interpretada conforme a Constituição (verfassungskonforme Auslegung), pode ser que se tenha a redução dessa discricionariedade. Poderá, nesse caso, ser percebido que os direitos fundamentais ou as tarefas impostas ao Estado pela Constituição já não sustentam a tal margem de liberdade. Assim, a autolimitação é gerada pela conduta do gestor público ou pela edição de norma jurídica, e tem por efeito reduzir a discricionariedade originariamente conferida pelo direito (CARVALHO, 2015, p. 116). Ela é realizada por um conjunto de instrumentos diversos, mas complementares, que pretendem assegurar a razoabilidade, a coerência e a isonomia no tratamento conferido pela Administração Pública em relação aos cidadãos. Por isso que pode ser considerada uma expressão do Estado Democrático de Direito e do devido processo legal substancial, que vedam as iniquidades estatais (ARAGÃO, 2008, p. 552).

É como se fosse possível visualizar a ocorrência de “comportamentos” reiterados adotados com base nos mesmos elementos fáticos, o que incute “confiança legítima” na sua conservação. Logo, eventual contradição ou desconformidade em face de condutas anteriormente externadas, no mínimo não é recomendável, sob pena de se ter a necessária reparação.

Há a imposição de um "dever de coerência no decidir", o que gera, por conseguinte, o surgimento regular de direitos subjetivos, de modo a homenagear os princípios da boa-fé e da

\footnotetext{
15 No Brasil, consultar obra específica sobre o tema: CARVALHO, 2015, p. 111 et seq., especialmente a partir do Capítulo 3.

16 O termo "autolimitação administrativa” pode ser traduzido pela expressão alemã "Selbstbindung der Verwaltung”. Cf., v.g. quanto ao uso do termo, BACIGALUPO, 1997, p. 119.
} 
segurança jurídica. Assim, o aporte de reiteradas condutas pode causar a solidificação de um padrão, lastreado na concentração de manifestações anteriores no mesmo sentido, ou seja, quase que se “fixando” um “pré-julgamento” para situações futuras (PIELOW, 1997, p. 49). Assim, devem ser investigadas as balizas à imposição de um “dever de coerência no decidir”.

Para tanto, os elementos e pressupostos à configuração de um precedente administrativo vinculante normalmente derivam de considerações dotadas de certa vagueza, ou por meio de conceitos jurídicos indeterminados ou de cláusulas gerais. Daí por que a formação de um precedente administrativo se mostra importante como mecanismo de tutela da proteção substancial da confiança legítima.

Para que exista a formação do precedente - entendido, de acordo com o que foi exposto, como uma categoria jurídica a designar uma decisão administrativa vinculativa - é necessário que: (a) seja construído a partir de um número significativo de casos - sendo que esse número deve ser expressivo em termos de qualidade, e não necessariamente de quantidade;

(b) seja reiterado o parâmetro decisório, a formatar uma diretriz;

(c) essas diretrizes decisórias sejam válidas;

(d) essas decisões sejam publicitadas pelos meios adequados, a fim de que seja suficiente ou possível o conhecimento delas.

Além disso, mostra-se imprescindível que se externe a pertinente motivação quando da formação do precedente, o que reclama a exposição lógico-sistemática dos motivos de fato e de direito $^{17}$. E isso permite saber se o precedente vincula ou não.

Essa mesma providência deve ser tomada quando se deixe de aplicar as decisões vinculativas firmadas - conforme dispõe a determinação constante na Lei do Processo Administrativo Federal (Lei $\mathrm{n}^{0}$ 9.784/199918), impondo que se tenha a pertinente motivação. A mudança de parâmetro, então, deve ser fundamentada com clareza e coerência, bem como deve ser lógica a exposição dos fundamentos ${ }^{19}$. A motivação não pode ser meramente formal, mas sim, que detenha efetividade bastante a gerar uma justificação razoável.

17 Aqui, não é demais lembrar a incidência dos parâmetros à motivação definidos no art. 50 da Lei nº 9.784/1999 (ainda que essa legislação seja incidente no âmbito da União, salvo quando, por analogia, é aplicada aos demais entes federados que não tenham editado sua lei de processo administrativo) e na Lei no 13.655/2018.

18 Lei no 9.784/1999, art. 50: “Os atos administrativos deverão ser motivados, com indicação dos fatos e dos fundamentos jurídicos, quando: [...] VII - deixem de aplicar jurisprudência firmada sobre a questão ou discrepem de pareceres, laudos, propostas e relatórios oficiais”. Conferir, ainda, o disposto no art. $2^{\circ}$, parágrafo único, inciso XIII, do mesmo dispositivo legal.

19 Logo, quando se promover uma espécie de “overruling” nas decisões administrativas, é imprescindível lançar mão de suficiente motivação, conforme dispõe o art. 50, inciso VII, da Lei nº 9.784/1999. 
Ademais, com base na juridicidade dos atos administrativos, há de se ter resguardados os direitos fundamentais, especialmente aqueles que protegem a segurança das relações jurídicas (exemplo: art. 50, inciso XXXVI, da CF/1988: garantia do ato jurídico perfeito, da coisa julgada e do direito adquirido). Mas não só isso. Devem ser garantidos, também, os direitos fundamentais atrelados ao devido processo legal (formal e substancial). Aqui, causa relevo a necessidade de que, previamente a qualquer mutação no entendimento ou violação do parâmetro firmado, seja dada a oportunidade de ampla defesa e contraditório.

Também, como garantia da segurança jurídica, a mudança de interpretação que rompa com um parâmetro fixado não pode retroagir e atingir situações consolidadas antes do advento do câmbio. Enfim, a mudança deve ser ultrativa ou prospectiva, referindo-se somente a situações futuras. Aplica-se, aqui, o disposto no art. $2^{\circ}$, inciso XIII, da Lei $n^{\circ} 9.784 / 1999$, o qual determina que, em processo administrativo federal, deve ser observado o critério de “[...] interpretação da norma administrativa da forma que melhor garanta o atendimento do fim público a que se dirige, vedada aplicação retroativa de nova interpretação”.

Além disso, não se admite que se aplique o “sistema administrativo de precedentes” que se basearam em fundamentos ilegais ou fatos falsos. Se as anteriores decisões administrativas expedidas foram reputadas ilegais - contrárias ao direito -, não se pode utilizar do princípio da igualdade como pano de fundo para se perpetuar uma conduta contrária à lei. Imagine-se que a Administração Pública, por três oportunidades, abstenha-se de exigir dos contratantes a documentação que comprove a “regularidade fiscal” (art. 27, inciso IV, da Lei nº 8.666/1993). Em uma quarta oportunidade, o Estado inabilita os contratantes que não juntaram esses documentos. No caso em apreço, não se pode alegar violação à isonomia ou pretender aplicar a mencionada “jurisprudência administrativa”, uma vez que não se pode perpetuar, como dito, decisões ou atitudes que sejam contrárias à lei ${ }^{20}$.

Vale dizer, portanto, que a aplicação do sistema de precedentes ou da jurisprudência administrativa jamais pode servir de fundamento para que se repitam decisões incorretas. Não podem servir de "pano de fundo" para que o erro se perpetue.

O precedente administrativo cria um dever no sentido de que a Administração Pública não deva modificar de forma injustificada as orientações fornecidas (MORAES, 1999, p. 120), salvo a previsão ou ocorrência de uma realidade assim autorize. Até porque as condutas estatais devem ser confiáveis, como premissa basilar da segurança jurídica. Vale dizer que a formação de um padrão de comportamento por reiteração de condutas ou de decisões tem por fundamento a proteção da

20 STF, MS nº 15.816-DF, Rel. Min. Luiz Gallotti, Pleno, j. 24/11/1965. 
confiança (CANOTILHO, 2003, p. 257; CASSESE, 1994, p. 251; CHAPUS, 2001, p. 105-107; COUTO E SILVA, 2005, p. 5; DI PIETRO, 2015, p. 39; HEINEN, 2019; MARRARA, 2012, p. 568569; MAURER, 2007, p. 59; PÉREZ, 2009, p. 55-60; SCHØNBERG, 2000).

Para exemplificar, cita-se julgado do Conselho de Estado francês. Trata-se do caso Société Tropic travaux signalisation, de 16 de julho de $2007^{21}$, momento em que se decidiu que a mudança da jurisprudência não poderia ser praticada em detrimento da segurança jurídica ${ }^{22}$. Assim, a partir do precedente mencionado, permitiu-se a abertura do recurso por excesso de poder ou pelo pleno contencioso para discutir os contratos administrativos - o que antes sempre fora uma matéria impossível de ser objeto dessas vias impugnativas. Contudo, ao mesmo tempo que a corte de justiça francesa permitiu a abertura do recurso a esses casos, decidiu, em homenagem à segurança jurídica, que os contratos em curso não poderiam sofrer o influxo do câmbio jurisprudencial, ou seja, ser objeto dos mencionados recursos (COLIN, 2011, p. 163).

\section{ALTERAÇÃO DO PRECEDENTE ADMINISTRATIVO - OVERRULING}

Avançando no tema, deve-se destacar que existem certas situações nas quais se verifica a possibilidade de mudança de padrão decisório. Para que se tenha a devida segurança jurídica, quando da modificação dos precedentes, é necessário estabelecer um método às possíveis modificações de entendimento. Apesar de o ordenamento jurídico-administrativo não ter detalhado uma metodologia clara nesse sentido, pensa-se que, por analogia, podem-se utilizar as ferramentas processuais e o método do sistema anglo-saxão - common law. Afinal, trata-se de um sistema jurídico historicamente construído, e que há longa data tem concebido os precedentes como fonte primária do direito. Há de se concentrar em duas hipóteses em que o precedente não se aplica: nos casos de superação (overruling) e de distinção (distinguishing) ${ }^{23}$.

No primeiro caso, a Administração Pública passaria a superar o precedente, ou seja, trataria de modificá-lo. No segundo caso, provar-se-ia que o precedente não se aplicaria, o que permitiria sua distinção (distinguishing). Lembrando-se que há distinção entre o caso concreto em julgamento

21 CE, 16 jul. 2007, Société Tropic travaux signalisation. O precedente foi referendado, posteriormente, pelo julgado CE, 11 mai. 2011, Société Rebillon Schmit Prévot.

22 Para as premissas teóricas aqui expostas, não possui relevância o fato de que a jurisprudência administrativa francesa tem caráter jurisdicional, e a brasileira não.

23 Egon Bockmann Moreira e Gabriel Jamur Gomes (2018, p. 262) também entendem que os parâmetros presentes no âmbito do processo civil para a revisão de um precedente podem ser aplicados ao processo administrativo. E isso pode ser retirado, também, da disposição expressa contida no art. 15 do CPC. Para uma compreensão ainda mais específica quanto ao tema, consultar: MOREIRA, 2016. 
e o paradigma, quando os fatos entre ambos os casos a serem comparados são diversos, ou porque há um dado peculiar que os distingue. É um termo utilizado para:

(a) referir-se à técnica de comparar os julgamentos em causa; ou

(b) designar o resultado dessa comparação. Pode o magistrado, na hipótese, aplicar o paradigma, mesmo havendo diferença, o que permite dizer que ele amplia o paradigma, ou não o aplica ${ }^{24}$.

Assim, a decisão administrativa que não aplica o precedente, ou seja, não autovinculante, somente poderá se legitimar diante de uma motivação que guarde os parâmetros logo antes mencionados, de modo que deverá estar baseada em argumentos que provem que a situação apresentada se mostra diversa ou foi superada. Em melhores termos: o Poder Público deverá demonstrar as razões de fato e de direito que apontam que a realidade presente é diversa daquela apresentada quando do pedido inicial, e que o precedente não se adapta a essa realidade, tal qual ocorre com a técnica do distinguishing.

Exemplificativamente, podem ser expostos alguns casos em que é admitida a mudança a jurisprudência administrativa, sem que se garanta qualquer manutenção da situação atual, com base em um precedente lastreado sobre outro contexto, por conta da aplicação da autovinculação administrativa:

(a) o caso anterior foi julgado com base em outro direito; ou

(b) quando, apesar de a fundamentação de direito ser a mesma, existir a possibilidade de se conferir outra interpretação, por conta de a anterior estar desatualizada ou incorreta; ou

(c) quando o caso anterior tinha por base outra situação de fato. Exemplo: a decisão administrativa entendeu por praticar uma medida de polícia, sem ofertar ampla defesa e contraditório prévios, dado que se estava diante de uma situação de emergência. Em outro momento, certo ato de polícia será praticado em situação normal, o que, claro, já reclama o contraditório e a ampla defesa prévios. Assim, essas duas decisões administrativas não se vinculam, porque refletem realidades diferentes.

\section{CONCLUSÕES}

A autolimitação se traduz em um "substrato teórico-dogmático instrumental”, na medida em que este mecanismo pode servir de ferramenta jurídica para ofertar respostas jurídicas aos efeitos ou ao descumprimento do art. 30 da LINDB. Pelo que foi exposto, é evidente que a institucionalização

\footnotetext{
24 Apresenta-se, aqui, uma síntese que se concentrou em duas ferramentas utilizadas para não aplicar o precedente. Contudo, o sistema processual anglo-saxão apresentaria outras mais, tendo em vista que ele é, nesse aspecto, bastante refinado. Sobre o tema, entre outros, consultar: FARNSWORTH, 1963 (essa obra oferece uma noção global do sistema jurídico do common law americano).
} 
de uma dogmática dos precedentes administrativos, como visto, não impede que a Administração Pública modifique seu entendimento. Por mais que se tenha, ao longo do tempo, assentada determinada diretriz interpretativa, a modificação é plenamente possível, até para o fim de acompanhar o câmbio da realidade que perpassa. Contudo, essa modificação deve respeitar determinados critérios, já expostos.

Assim, de acordo com o que foi proposto logo na introdução, pretende-se sistematizar a aplicação do mencionado mecanismo de autolimitação administrativa. Para tanto, estruturou-se didaticamente o que se considera necessário observar para a aplicação da autovinculação administrativa no que se refere à jurisprudência ou aos precedentes administrativos. É necessário ${ }^{25}$ : (A) margem positiva (elementos que devem estar presentes para aplicar a teoria):

(a1) estar diante de decisões administrativas reiteradas;

(a2) basear-se em circunstâncias análogas ou a aplicar o mesmo direito;

(a3) que essas decisões provenham da mesma pessoa jurídica de direito público, ou seja, não podem advir de entes diversos (não necessariamente os precedentes devem ser reiterados pelo mesmo órgão, salvo se se tratar de situações específicas ou peculiares).

(B) Margem negativa (elementos que não devem estar presentes para aplicar a teoria). Assim, não se aplica a autovinculação:

(b1) quando existe lei permitindo expressamente a mudança de padrão decisório. No caso, é possível a mudança do precedente ou sua distinção quando: ou ele não se aplica ao caso específico distinguishing; ou ele não deve mais ser aplicado - overruling;

(b2) quando a decisão ou as decisões administrativas-paradigma são ilegais, ou se baseiam em uma realidade falsa;

(b3) quando a decisão for apta a modificar decisões pretéritas.

(C) Requisitos procedimentais. É necessário que:

(c1) exare-se suficiente motivação;

(c2) caso exista distinção ou modificação do precedente, a autoridade pública cientifique os interessados, deixando transparente essa mudança, bem como garanta a ampla defesa e o contraditório;

(c3) a mudança não seja retroativa;

(c4) caso a decisão venha a estabelecer interpretação ou orientação nova sobre norma de conteúdo indeterminado, impondo novo dever ou novo condicionamento de direito, preveja regime de

25 E, aqui, também, de certo modo, apresentam-se os elementos dogmáticos para aplicação da autolimitação administrativa com base nos precedentes administrativos. 
transição quando indispensável para que o novo dever ou condicionamento de direito seja cumprido de modo proporcional, equânime e eficiente e sem prejuízo aos interesses gerais ${ }^{26}$.

\section{REFERENCIAS}

ALMEIDA, Fernando Dias Menezes de. Memória jurisprudencial: Ministro Victor Nunes. Brasília: Supremo Tribunal Federal, 2006.

ARAGÃO, Alexandre Santos. Teoria das autolimitações administrativas atos próprios, confiança legítima e contradição entre órgãos administrativos. Boletim de Direito Administrativo, São Paulo, v. 24, n. 5, p. 552-561, maio 2008.

BACIGALUPO, Mariano. La discrecionalidad administrativa (estructura normativa, control judicial y límites constitucionales de su atribución). Madri: Marcial Pons, 1997.

BRASIL. Constituição da República Federativa do Brasil de 1988. Brasília, Diário Oficial da União, 5 out. 1988. Disponível em: https://bit.ly/3th5d9c. Acesso em: 20 maio 2020.

BRASIL. Decreto-Lei no 4.657, de 4 de setembro de 1942. Lei de Introdução às normas do Direito Brasileiro. Rio de Janeiro, Diário Oficial da União, 9 set. 1942, retificado em 8 out. 1942 e retificado em 17 jun. 1943. Disponível em: https://bit.ly/2Rwd050. Acesso em: 20 maio 2020.

BRASIL. Lei n ${ }^{\circ}$ 8.666, de 21 de junho de 1993. Regulamenta o art. 37, inciso XXI, da Constituição Federal, institui normas para licitações e contratos da Administração Pública e dá outras providências. Brasília, Diário Oficial da União, 22 jun. 1993, republicado em 6 jul. 1994 e retificado em 6 jul. 1994. Disponível em: https://bit.ly/2ONwxgg. Acesso em: 20 maio 2020.

BRASIL. Lei ${ }^{\circ}$ 9.784, de 29 de janeiro de 1999. Regula o processo administrativo no âmbito da Administração Pública Federal. Brasília, Diário Oficial da União, 1 fev. 1999, retificado em 11 mar. 1999. Disponível em: https://bit.ly/3tlZcbq. Acesso em: 20 maio 2020.

BRASIL. Lei nº 13.105, de 16 de março de 2015. Código de Processo Civil. Brasília, Diário Oficial da União, 17 mar. 2015. Disponível em: https://bit.ly/32dxqSc. Acesso em: 20 maio 2020.

CADORE, Márcia Regina Lusa. Súmula vinculante e uniformização de jurisprudência. São Paulo: Atlas, 2007.

CANOTILHO, José Joaquim. Direito constitucional e teoria da constituição. Coimbra: Almedina, 2003.

CARVALHO, Gustavo Marinho de. Precedentes administrativos no direito brasileiro. São Paulo: Contracorrente, 2015.

CASSESE; Sabino. Las bases del derecho administrativo. Madrid: INAP, 1994.

26 Incidência do art. 23 da LINDB, com redação dada pela Lei nº 13.655/2018. 
CAVALCANTI, Themístocles. Tratado de direito administrativo. V. 4. Rio de Janeiro: Freitas Bastos, 1956.

CHAPUS, René. Droit administratif géneral. T. 1. Paris: Montchrestien, 2001.

COLIN, Frédéric. L’essentiel des grands arrêts du droit administratif. 2011-2012. Paris:

Gualino, 2011.

COUTO E SILVA, Almiro do. O Princípio da Segurança Jurídica (Proteção à Confiança) no Direito Público Brasileiro e o Direito da Administração Pública de Anular seus Próprios Atos Administrativos: o prazo decadencial do art. 54 da lei do processo administrativo da União (Lei ${ }^{\circ}$ 9.784/99). Revista Eletrônica de Direito do Estado, Salvador, n. 2, abril-maio-junho, 2005.

DI PIETRO, Maria Sylvia Zanella. Direito administrativo. São Paulo: Atlas, 2015.

FARNSWORTH, E. Allan. Introdução ao sistema jurídica dos Estados Unidos. Rio de Janeiro: Forense, 1963.

GAMBOA, Jaime Orlando Santofimio. La fuerza de los precedentes administrativos en el sistema jurídico del derecho positivo colombiano. Bogotá: Universidad Externado de Colombia, 2010.

HART, Herbert L. A. O conceito de direito. Lisboa: Fundação Calouste Gulbenkian, 2005.

HEINEN, Juliano. Autolimitação administrativa e segurança jurídica. Direito, Estado e Sociedade, Rio de Janeiro, n. 52, p. 159-176, jan.-jun. 2018.

HEINEN, Juliano. Segurança jurídica no direito estrangeiro e brasileiro. Meritum, Belo Horizonte, v. 14, n. 1, p. 347-371, jan.-jun. 2019.

KELSEN, Hans. Teoria pura do direito. São Paulo: Martins Fontes, 1995.

LAWTEACHER. Doctrine of Judicial Precedent Lecture. November 2013. Disponível em: https://bit.ly/3g8slmk. Acesso em: 20 maio 2020.

LUENGO, Javier Garcia. El principio de protección de la confianza en el derecho administrativo. Madrid: Civitas, 2002.

LUVIZOTTO, Juliana Cristina. Precedentes administrativos \& vinculação da atividade administrativa. Curitiba: Juruá, 2017.

MACCORMICK, Neil; SUMMERS, Robert. Interpreting precedents: a comparative study (applied legal philosophy). Farnham: Ashgate, 1997.

MARINONI, Luiz Guilherme. Precedentes obrigatórios. São Paulo: Revista dos Tribunais, 2010.

MARRARA, Thiago. A boa-fé do administrado e do administrador como fator limitativo à discricionariedade administrativa. Boletim de direito administrativo, São Paulo, maio 2012. 
MAURER, Hartmut. Contributos para o direito do Estado. Porto Alegre: Livraria do Advogado, 2007.

MAXIMILIANO, Carlos. Hermenêutica e aplicação do Direito. Rio de Janeiro: Forense, 2011.

MELLO, Oswaldo Aranha Bandeira de. Princípios gerais de direito administrativo. V. 1. São Paulo: Malheiros, 2010.

MITIDIERO, Daniel. Precedentes - da persuasão à vinculação. São Paulo: Revista dos Tribunais, 2017.

MORAES, Germana de Oliveira. Controle jurisdicional da administração pública. São Paulo: Dialética, 1999.

MOREIRA, Egon Bockmann. O novo Código de Processo Civil e sua aplicação no processo administrativo. Revista de Direito Administrativo, Rio de Janeiro, v. 273, p. 314-334, set.-dez. 2016.

MOREIRA, Egon Bockmann; GOMES, Gabriel Jamur. A indispensável coisa julgada administrativa. Revista de Direito Administrativo, Rio de Janeiro, v. 277, n. 2, p. 239-277, maioago. 2018.

MOREIRA, Egon Bockmann; PEREIRA, Paula Pessoa. Art. 30 da LINDB. O dever público de incrementar a segurança jurídica. Revista de Direito Administrativo, Rio de Janeiro, Edição Especial: direito público na Lei de Introdução às Normas de Direito Brasileiro - LINDB (Lei no 13.655/2018), p. 243-274, nov. 2018.

OLIVEIRA, Rafael Carvalho Rezende. Precedentes no direito administrativo. São Paulo: Editora Gen, 2018.

OTERO, Paulo. Legalidade e administração pública: o sentido da vinculação administrativa à juridicidade. Coimbra: Almedina, 2003.

PÉREZ, Jesús González. El principio general de la buena fe en el derecho administrativo. Madrid: Civitas/Thompson Reuters, 2009.

PIELOW, Johann-Christian. Integración del ordenamiento jurídico: autovinculaciones de la adminitración. In: MUÑOZ, Guillermo Andrés; SALOMONI, Jorge Luis. Problemática de la administración contemporânea: uma comparación europeo-argentina. Buenos Aires: Ad-Hoc, 1997.

SADDY, André. A administração pública e códigos de conduta. Revista de Direito Administrativo, São Paulo, n. 262, p. 233-261, abr. 2013.

SASTRE, Silvia Díez. El precedente administrativo: fundamentos y eficácia vinculante. Madrid: Marcial Pons, 2008.

SCHØNBERG, Søren. Legitimate expectations in administrative law. Oxford: Oxford University Press, 2000. 
TARELLO, Giovanni. L’interpretazione della legge. Milano: Giuffré, 1980. 